\title{
Si me permiten hablar...: la subjetivación plural en el relato testimonial de Domitila Chungara
}

If you allow me to speak: the plural subjectivation in the testimonial narrative of Domitila Chungara

\author{
ROCío ZaVALA VirReira \\ UNIVERSITÉ CATHOLIQUE DE LILLE·rocizavala@hotmail.com \\ Doctora en Literatura hispanoamericana por la Universidad Charles de Gaulle, Lille 3 \\ Miembro asociada del Laboratorio CECILLE, Centro de estudios en civilizaciones, lenguas \\ y literaturas extranjeras. EA 4074, Universidad Lille 3. Docente de la Universidad Católica \\ de Lille. Investiga sobre Hilda Mundy, vanguardia literaria hispanoamericana, literatura \\ boliviana de comienzos del siglo XX, literaturas de la guerra del Chaco, voces de mujeres, \\ procesos de subjetivación.
}

RECIBIDO: 14 DE OCTUBRE DE 2015

DOI: 10.7203/KAM.6.7078

ACEPTADO: 20 DE NOVIEMBRE DE 2015

ISSN: 2340-1869

Resumen: Este artículo aborda la cuestión de la subjetivación plural en el testimonio de Domitila Chungara Si me permiten hablar... ¿Cómo se construye esa palabra que Domitila Chungara elabora como la voz de su pueblo? ¿Qué dice esta voz acerca del desencuentro discursivo que persiste entre, por un lado, quienes privilegian ciertas categorías subjetivas en nombre de la visibilidad de ciertas luchas y, por otro lado, quienes plantean un pensamiento interseccional del sujeto histórico oprimido?

Palabras clave: testimonio, Domitila Chungara, subalternidad y autoría plural.
Resumen: This paper deals with the issue on plural subjectivation on Domitila Chungara's testimony $\mathrm{Si}$ me permiten hablar... How does Chungara elaborate her voice as the people's voice? What does this voice reveal about the multiple dimensions of subject. specially about race, gender and class?

Palabras clave: Testimony, Domitila Chingara, Subalternity y Plural Author. 
Este estudio abordará el libro "Si me permiten hablar..." Testimonio de Domitila, una mujer de las minas de Bolivia de 1977, considerado, junto con el libro de 1983 Me llamo Rigoberta Menchú y asíme nació la conciencia, como paradigmas en la escritura testimonial de mujeres, y a cuya particularidad se añade la de ser la voz de las sin voz: una subalternidad tejida de las categorías de etnia, clase y género.

Domitila Barrios de Chungara (Siglo XX, Potosí, 1937-Cochabamba, 2012), más conocida como Domitila Chungara, líder de la clase trabajadora, supo alzar su voz de denuncia política en los peores años de la violencia represiva del Estado boliviano hacia la izquierda insurgente: años 60, $70 \mathrm{y}$ comienzos de los años 80, marcados a sangre y fuego por las dictaduras militares. Si me permiten hablar... aparece en un momento decisivo de la trayectoria política de la protagonista: la caída de la dictadura del general Hugo Bánzer Suárez que gobernaba en Bolivia desde 1971¹.

Recordemos que el libro se originó en la Tribuna del Año internacional de la mujer, organizada en México en 1975 por las Naciones Unidas, cuando la educadora brasileña Moema Viezzer, impactada por la palabra divergente de la boliviana, le propuso recoger su testimonio para publicarlo. Señalemos igualmente que este libro, bastante convocado por los estudios feministas hispánicos, se reclama abiertamente antifeminista a partir del encuentro de Domitila Chungara con el feminismo institucional en dicho evento internacional. Cuenta la narradora cómo las organizadoras limitaron e incluso censuraron su palabra, al ser la misma una palabra que, más que de una opresión femenina, venía a hablar de la opresión de todo un pueblo. Así, Domitila Chungara rechazó de entrada una palabra unívoca que expresara los problemas comunes de una mujer supuestamente universal, al apuntar abiertamente las diferencias de clase que separaban a unas de otras.

A partir de ese desencuentro discursivo entre las voces de mujeres, este trabajo pretende hacer una lectura del texto con la referencia de un pensamiento que desde los años 70, justamente, y originados principalmente en los estudios de Michel Foucault, está teorizando los procesos de construcción del sujeto histórico oprimido a través de su genealogía, del recuento de sus experiencias dentro de sus relaciones de poder. ¿Cómo se construye esa palabra que Domitila Chungara elabora como la voz de su pueblo? ¿Qué dice esta voz acerca del desencuentro discursivo que persiste entre, por un lado, quienes privilegian ciertas categorías subjetivas en nombre de la visibilidad de ciertas luchas y, por otro lado, quienes plantean un pensamiento interseccional del sujeto histórico oprimido?

\footnotetext{
${ }^{1}$ En la Navidad de 1977, un grupo de cinco mujeres inician en La Paz una huelga de hambre en enfrentamiento al gobierno de Bánzer Suárez. Esta huelga de hambre, que se multiplicó masivamente tras el ejemplo de esas cinco mujeres, provocó una crisis que culminó con la caída del dictador unos meses después. Domitila Chungara fue una de esas cinco huelguistas que vencieron la dictadura de los años 70.
} 
Rocío Zavala. Si me permiten hablar...

Lavoz

El testimonio de Domitila Chungara comienza con la caracterización de la voz, no como individuo sino como sujeto, es decir como voz de un ser social, inseparable de las categorías sociales que lo determinan:

La historia que voy a relatar, no quiero en ningún momento que la interpreten solamente como un problema personal. Porque pienso que mi vida está relacionada con mi pueblo. Lo que me pasó a mí, le puede haber pasado a cientos de personas en mi país. Esto quiero esclarecer, porque reconozco que ha habido seres que han hecho mucho más que yo por el pueblo, pero que han muerto o no han tenido la oportunidad de ser conocidos. (Viezzer, 1978: 13).

El “yo" de Domitila Chungara que se dice “pueblo”, tuvo gran repercusión en su época, pese a sus divergencias con la posición dominante. Dice Moema Viezzer en la introducción del libro:

Única mujer de la clase trabajadora que participó activamente en la Tribuna en representación de Bolivia, sus intervenciones produjeron un profundo impacto entre los presentes. Eso se debió, en gran parte, a que "Domitila vivió lo que otras hablaron", según el comentario de una periodista sueca. (Viezzer, 1978: 1).

Ese "vivir lo que otras hablan", hizo y hace de este testimonio un objeto fundamental dentro de la perspectiva fenomenológica de los estudios de género. La fenomenología que consiste en hacer tabla rasa de los conceptos preestablecidos en favor del análisis de lo vivido como fundamento del conocimiento, ha sido uno de los pilares del pensamiento foucaltiano de la subjetivación ${ }^{2}$. Las nociones de sujeto y de subjetividad retoman, en este trabajo, la búsqueda por parte de Michel Foucault, de una aprehensión del sujeto dentro de su trama histórica (Revel, 2008: 129). Y Moema Viezzer, que transcribe y estructura el testimonio de Domitila, intitula la cubierta del libro como "Historia inmediata", inscribiendo así la obra en la relación vivida entre el "yo" y su mundo en un sentido que es el sentido de una historia y de una cultura que cambian en el tiempo.

La palabra de Domitila que va tejiendo esta historia inmediata a partir del recuerdo de lo vivido en un sendero marcado por la condición social, revela un relato nutrido de lecturas marxistas ampliamente mayoritarias en el medio sindical minero de los años 60 y 70. Así, este testimonio comprende exposiciones didácticas -incluso con terminología económica y financiera- que pueden ocupar varias páginas, lo que no parece estar de más cuando se habla de un país que ha difundido tan poco su historia.

\footnotetext{
${ }^{2}$ La subjetivación o el proceso que la determina es, para Foucault, la constitución del sujeto; un sujeto fundamentalmente histórico puesto que su genealogía -su trama histórica- es la base de su estudio; una genealogía conformada por lo que Foucault llama las ontologías históricas de: el saber (la verdad del sujeto, los discursos de la experiencia del sujeto provenientes de voces ocultadas, por ejemplo); el poder (la normatividad, los mecanismos de control y represión de su entorno); y la moral (las relaciones de dominación de la experiencia erótica en el espacio doméstico). Cf. M. Foucault. Dits et écrits, IV, 1954-1988. Paris: Gallimard, 1994, p. 393.
} 
Y en cualquier caso, de todo ello surge esta voz que se dice como sujeto histórico dentro de una trama en la que se manifiesta ampliamente la diversidad de su propio ser y, asimismo, la diversidad en distintas voces tanto de mujeres como de hombres. La cuestión de clase es el hilo conductor del relato de Domitila. Y sin embargo este libro muestra mucho más que la lucha del pueblo trabajador minero y de sus condiciones de vida: a través de lo vivido, el sujeto mujer, trabajadora, emparentada con el mundo indígena campesino, aparece bajo diversas lógicas de dominación que problematizan a su vez la categoría de clase $^{3}$.

Si me permiten hablar..., revela la voz singular de una mujer que habla con sus propias palabras, con un ritmo que es el suyo, y que avanza con sus dudas, con cuestionamientos permanentemente dirigidos hacia su propio discurso. El estilo interrogativo y a veces dubitativo del testimonio es la marca patente de esa aprehensión inmediata de la coyuntura histórica y es, al mismo tiempo, la marca de una condición subalterna en la intersección de su condición de mujer minera, de extracción indígena, pobre, y por ello con una educación precaria y sin embargo trabajada voluntariosamente pese a todas las dificultades ${ }^{4}$.

La experiencia como fundamento inalienable de la constitución del sujeto histórico hace de la circunstancia histórica de Domitila Chungara un conjunto de informaciones que darán cuenta de los mecanismos y estrategias de dominación para constituir su genealogía.

\section{Su trama histórica}

Es Domitila Chungara una mujer de las minas, trabajadora no asalariada, esposa de un trabajador minero, ama de casa y participante de la vida sindical a través del 'Comité de amas de casa' fundado en 1961. Trabajadora de las minas de los Andes que desde comienzos del siglo XX y hasta los años 70, han hecho de Bolivia el segundo productor mundial de estaño. La localidad natal de la protagonista -Siglo XX, departamento de Potosí- constituía, junto a otros, "el centro minero más grande de Bolivia, con más experiencia revolucionaria y donde ha habido más masacres por parte de los gobiernos de

\footnotetext{
${ }^{3}$ Tal como ilustra el pasaje en que Domitila narra cómo el gobierno de Paz Estenssoro (2º gobierno: 1960-1964) enfrentó a los campesinos de Ucureña (Cochabamba) y a los mineros de Siglo XX mediante falsos rumores y denuncias (Viezzer: 91-92). Esta táctica del poder político para debilitar la resistencia crea antagonismos que pueden implicar aspectos étnicos indígenas cuando la gran mayoría del proletariado minero boliviano es indígena. Por otra parte, cuando la narradora habla de su experiencia con los campesinos de la región subtropical de La Paz y de la gran diferencia en cuanto a la conciencia política muy desarrollada en los mineros (Viezzer: 177), sale a relucir en ese contexto histórico, la prevalencia de la categoría de clase por sobre la étnica.

${ }^{4}$ Tal como cuenta el capítulo sobre las dificultades por ingresar a la escuela a causa de la pobreza de sus padres, y sobre todo por continuar sus estudios a partir de la muerte de su madre siendo Domitila adolescente y debiendo desde entonces ocuparse de sus hermanas (Viezzer: 51-60)
} 
turno" (Viezzer, 1978: 19). Así ilustra Domitila el contexto de gran tensión entre la izquierda revolucionaria y la lucha antisubversiva. Se trata de la Bolivia posrevolucionaria que había nacionalizado las minas en 1952: una revolución estatista que consolidó el fin del Estado oligárquico y que, en un país mayoritariamente indígena, transformó el relato nacional haciéndolo menos excluyente. Las banderas revolucionarias del 52 fueron, sin embargo, rápidamente traicionadas, entre otros, por intereses partidarios, y los regímenes militares autoritarios retornaron a la escena política boliviana a partir de 1964 con el General Barrientos Ortuño.

Si me permiten hablar... da cuenta del antecedente revolucionario y posrevolucionario de la misma manera como lo hace a lo largo del libro: a través de la percepción subjetiva de su circunstancia, mediante sus recuerdos de infancia -mayormente en este caso-, a través de la experiencia del padre: ex combatiente de la guerra del Chaco contra el Paraguay (1932-1935), partidario y luchador de la revolución y cuyo itinerario de trabajador pobre dará a conocer una continuidad de abusos de poder que la Revolución del 52 no cambiaría sino retóricamente, y a veces ni eso. El espacio del relato girando fundamentalmente en torno a los centros mineros de estaño, epicentro de la actividad económica en la Bolivia de entonces, evoca también la historia grande de hombres y mujeres que fueron la vanguardia del proletariado boliviano hasta el cierre de las minas estatales tras el advenimiento del orden neoliberal en 1985. Al mismo tiempo, los recuerdos, las anécdotas, la historia chica, los comentarios, al sobreponerse al discurso histórico o a la exposición sociopolítica, logran un verdadero impacto narrativo que dice lo que no dice el discurso oficial, o -en virtud de la desjerarquización del punto de vista- dice a veces mucho más y con más fuerza. Al hablar, por ejemplo, de su itinerario de formación política y sindical, Domitila se burla también de la palabra especializada e intrincada de ciertos intelectuales de izquierda que intervenían en los centros mineros. La narradora puede o no detenerse en tales matices y grietas del relato de la experiencia del pueblo, y en tal caso hacerlo con vigor crítico, con ironía o con pura amargura en su denuncia. Al margen de la escritura testimonial y lo que ella dice del proceso de subjetivación de la protagonista, este texto revela capítulos ignorados por el discurso oficial y por ello cobra una importancia particular en cuanto al conocimiento de la condición de vida de mineros y mineras, así como la experiencia de sus resistencias.

Fundamentalmente, el sentido nuevo y diferente que va dibujando Domitila Chungara al revelar espacios de vida y de lucha protagonizados por otras voces, otras formas de organización y otras estrategias de resistencia que son del mundo de las mujeres, se va centrando en el órgano sindical que la verá surgir como dirigenta: el Comité de amas de casa del centro minero de Siglo XX. Ya el nombre del Comité habla de una relegación femenina al espacio doméstico, y es a través de la infancia de la protagonista que asistimos a la historia de la construcción de este destino y de la lucha en su contra. 
Rocío Zavala. Si me permiten hablar...

La figura del padre es muy importante y a la vez paradójica en el proceso de subjetivación de Domitila, pues pese a ser un padre violento (Cf. Viezzer: 62-65) permitió y alentó en sus hijas un espíritu de lucha exento de inferioridad con relación a los varones. La evocación del padre de la narradora es la de un verdadero contradictor del pensamiento machista de su medio; ese medio que habría hecho de Domitila un ama de casa más. Por otra parte su conciencia de clase tampoco está desvinculada de la politización del padre, de la huella histórica que dejó en él la guerra del Chaco, de la senda antioligárquica que abrió la guerra hasta la revolución de 1952. El sólido discurso identitario de clase de los mineros, sostenedores seculares del país, brazo armado a la vanguardia de la revolución a través del empoderamiento de los sindicatos, se refleja fuertemente en el apego y el orgullo sin ambages que expresa Domitila:

Yo pienso que el Sindicato, la Federación, la Central Obrera Boliviana son nuestras representaciones, son nuestra voz, y por esto debemos cuidarlas como a la niña de nuestros ojos (Viezzer, 1978: 37).

La lectura de los diferentes aspectos de vida en las minas que narra el libro, el relato de la lucha y la resistencia a la represión militar, revelan, como anota la autora brasileña: "el temple de la clase trabajadora boliviana y de las mujeres (Viezzer, 1978: 4).

\section{Género y clase}

Esa voz obrera, minera, apegada a sus organizaciones de base, constituye el bastión identitario que prevalecerá en la expresión de todas sus reivindicaciones; una identidad de clase a la que, llegado el caso, se apelará como referencia legítima y legitimadora de otras demandas, como en este caso para denunciar la violencia de género:

Hay compañeras que participan cuando algo muy especial ocurre. Por ejemplo, cuando convocamos a la manifestación para reclamar el aumento de cupo en el 73, unas cinco mil mujeres participaron. Y cuando volvieron a sus casas, muchos trabajadores las pegaron y dijeron que ellas eran amas de casa y que no tenían nada que ver con política y que su obligación era de estar en la casa. Hasta que, finalmente, nosotras dijimos que íbamos a hacer una crítica por la radio. Y la hicimos y dijimos: "Aquellos compañeros que pegaron a sus esposas deben ser agentes del gobierno. Sólo así se justifica que ellos estén en contra de que sus compañeras hayan pedido lo que en justicia nos corresponde. [...]” (Viezzer, 1978: 84).

La opresión genérica que sale de los episodios narrados, aparece aminorada por la gravedad de la explotación o de la persecución militar o policial, porque ésta última constituía en los hechos un peligro inminente de encarcelamiento, exilio o llanamente de muerte. La violencia física de género aparece en repetidas ocasiones en relación a su medio e igualmente por parte de su propio marido. Así en el 
episodio que relata su liberación tras un primer encarcelamiento en La Paz -prueba de fuego que revela la resistencia férrea de Domitila Chungara ante los golpes físicos y sicológicos-, ella es inmediatamente sometida a la persecución y a la represión policial que también se ejerce contra su marido a quien despiden en nombre del activismo de su mujer. Y cuando ella se reúne con él, a las diversas violencias vividas en la cárcel, se suma la violencia conyugal:

Allí en Oruro encontré a mi compañero tomando, con más ganas tomando. Cuando le pregunté:

- ¿Por qué estás tomando?

¡Uf!... más bien me pegó. Y me decía que por culpa mía estaba sin trabajo, que por culpa mía estaba tomando así, y que no le importaba a él eso que yo le contaba (Viezzer, 1978: 155).

La violencia estatal, policial o militar, así nominada, comentada y denunciada, no tiene su equivalente de denuncia en el caso de la violencia de género física y sicológica que sufre la narradora. La lucha de clases, agitando esta voz de canto a canto, orienta el análisis de la dominación hacia la mujer como el efecto, prácticamente exclusivo, de la ideología capitalista. El antifeminismo, expresado como tal por la narradora, no significa que la cuestión de la emancipación de la mujer no ocupe un lugar importante en el texto. Al contrario: el relato de su vida y particularmente de su vida de de mujer casada y con hijos es el testimonio crudo de una cotidianidad de trabajo extremo que además conoce la desvalorización o hasta la invisibilización, como en el caso de actividades comerciales que podían incluso generar mayores beneficios que el trabajo del varón. El testimonio de esta cotidianidad se dice como un acto de denuncia por la injusticia de tales desigualdades entre hombres y mujeres. Por otra parte Domitila expresa una palabra crítica particularmente en relación a la ocupación del espacio público por las mujeres, pero teniendo el mayor cuidado de articular su palabra de crítica dentro de la crítica anticapitalista:

Porque si uno tiene el enemigo dentro de su propia casa, entonces es un arma más que puede utilizar nuestro enemigo común con un fin peligroso. Por esto es bien necesario que tengamos ideas claras de cómo es toda la situación y desechar para siempre esta idea burguesa de que la mujer debe quedarse en el hogar y no meterse en otras cosas, en asuntos sindicales y políticos, por ejemplo. Porque, aunque esté solamente en la casa, de todos modos está metida en todo el sistema de explotación en que vive su compañero que trabaja en la mina o en la fábrica o en lo que sea, ¿no es cierto? (Viezzer, 1978: 36).

La explotación de la clase trabajadora por parte de la burguesía y los instrumentos gubernamentales a su servicio, se extienden para Domitila Chungara al ámbito privado. La ideología burguesa sería la autora de la relegación del rol social de la mujer al ámbito doméstico, como una táctica para invalidar su lucha sindical y política, para excluirla de la misma. Domitila cree en la emancipación de la mujer -fundamentalmente a través de la educación-, cree en el rol activo que debe ejercer en el espacio público, pero sobre todo cree que esta lucha se ganará necesariamente tras el triunfo del 
proletariado. Este razonamiento que lleva a la autora a una reflexión sobre la legitimación de su activismo, parte de una visión monolítica del feminismo. Es decir, una visión proveniente del discurso dominante en la Conferencia internacional de México y que en su afán de búsqueda de las especificidades y diferencias femeninas para revalorizarlas, se centraba en una identidad feminina común que no veía o no quería ver la existencia de otras opresiones comunes a mujeres y a hombres:

Porque nuestra posición no es una posición como la de las feministas. Nosotras consideramos que nuestra liberación consiste primeramente en llegar a que nuestro país sea liberado para siempre del yugo imperialista [...]. Entonces sí, vamos a tener más condiciones para llegar a una liberación completa, también en nuestra condición de mujeres.

Lo importante, para nosotras, es la participación del compañero y de la compañera en conjunto. Sólo así podremos lograr un tiempo mejor, gente mejor y más felicidad para todos. (Viezzer, 1978: 42).

Y su testimonio da las claves del itinerario de una minera que, fundamentando la historia de sus luchas en el antagonismo de clases, constituye una subjetividad de resistencia y de denuncia política. Su contacto con las teorías feministas es nulo y, por otra parte, su interiorización de convencionalismos familiares y sociales estructurados fuertemente por la Iglesia católica, la conducen a la idea del rol central de la mujer como esposa y madre. Es así que en 1975, tras la experiencia del régimen masacrador del general Barrientos Ortuño (1964-1965; 1966-1969), y posteriormente del general Bánzer Suárez (1971-1978), Domitila Chungara llega a México, cargando en la espalda la urgencia de una denuncia y una demanda de solidaridad hacia un pueblo sometido.

La percepción monolítica de la narradora en relación al feminismo, en el marco de lo que ella descubrió en dicha Tribuna internacional, revela la soledad de esta voz de la subalternidad en la intersección de otras explotaciones además de las de género. Esta soledad con relación a otras voces de mujeres en diversas intersecciones de la dominación, habla de la desconexión de las palabras de reivindicación y lucha. Lo contrario habría presentado un marco referencial diferente en el que la violencia sexual, física o sicológica, por ejemplo, hubieran podido leerse en el marco de otras luchas políticas. La ausencia de otras participantes activas de la clase trabajadora en la Tribuna de las Naciones Unidas $^{5}$, crea en la narradora una percepción sesgada por la desconfianza que le inspiran esas mujeres, mayormente privilegiadas y profesionales, en la perspectiva de un ama de casa del sector minero, cuyo acceso a la educación básica fue en sí una batalla plagada de sacrificios. Al ser la lucha por la emancipación de la mujer -para ella- una lucha subyacente en la lucha del proletariado, las reinvindicaciones feministas burguesas o pequeño burguesas que escucha, le aparecen de por sí como

\footnotetext{
${ }^{5}$ Como señala Moema Viezzer en su introducción (Viezzer, 1978: 1).
} 
voces opositoras. De hecho, la palabra feminista oficial del evento internacional se enfrentó a la minera, cuando una de las organizadoras le pidió que no hablara de política sino de "la mujer", de "nosotras". Esta interpelación dio lugar a la respuesta de Domitila Chungara, una toma de la palabra que recoge el libro y que es el corazón del mismo en cuanto testimonio de su subjetividad en la lucha y la denuncia:

[...] -si me permite, voy a empezar. Señora, hace una semana que yo la conozco a usted. Cada mañana usted llega con un traje diferente; y sin embargo, yo no. Cada día llega usted pintada y peinada como quien tiene tiempo de pasar en una peluquería bien elegante y puede gastar buena plata en eso; y, sin embargo, yo no. Yo veo que usted tiene cada tarde un chofer en un carro esperándola a la puerta de este local para recogerla a su casa; y, sin embargo, yo no. Y para presentarse aquí como se presenta, estoy segura de que usted vive en una vivienda bien elegante, en un barrio también elegante, ¿no? Y, sin embargo, nosotras las mujeres de los mineros, tenemos solamente una pequeña vivienda prestada y cuando se muere nuestro esposo o se enferma o lo retiran de la empresa, tenemos noventa días para abandonar la vivienda y estamos en la calle.

Ahora, señora, dígame: ¿tiene usted algo semejante a mi situación? ¿Tengo yo algo semejante a su situación de usted? Entonces, ¿de qué igualdad vamos a hablar entre nosotras? ¿Si usted y yo no nos parecemos, si usted y yo somos tan diferentes? Nosotras no podemos, en este momento, ser iguales, aun como mujeres, [...] (Viezzer, 1978: $225)$.

Descalificando tempranamente la voz que dice "nosotras, las mujeres", en el contexto de un evento internacional de tal magnitud en los años 70, Domitila Chungara descalifica una corriente poderosa del feminismo que desde escuelas diversas sigue trabajando el esencialismo femenino, apoyado generalmente en el biologismo de las diferencias.

Domitila, mediante un relato simple y a la vez crudo, demuestra la inexistencia de un sujeto político mujer "universal”. La cuestión de la pluralidad del sujeto político en Si me permiten hablar... parece como una verdadera interpelación del discurso feminista dominante en su contexto e ilustra una corriente más actual de los estudios feministas que plantean que la dominación es interseccional ${ }^{6}$. En Bolivia, el feminismo autónomo del colectivo Mujeres creando, hoy dividido pero aún activo y desde los años 90, dice:

[...] el género no es una categoría de análisis social que puede ser aplicada en su pureza. El género aislado, separado del conjunto de categorías sociales de comprensión de la sociedad no tiene ningún interés ni sentido. Y aplicada de manera aislada nos conduce a

\footnotetext{
${ }^{6}$ La noción de interseccionalidad, de 1989, le pertenece a Kimberlé Crenshaw, feminista afroamericana, quien difundió el término a partir de su artículo «Demarginalizing the Intersection of Race and Sex: A Black Feminist Critique of Antidiscrimination Doctrine, Feminist Theory and Antiracist Politics». El artículo fue publicado originalmente en la Revista University of Chicago Legal Forum, 1989 (disponible en línea).
} 
conclusiones erróneas como que existieran intereses comunes a todas las mujeres, perdiendo las contradicciones por las que estamos atravesadas. No existen intereses comunes a todas las mujeres de una sociedad, lo que existe es un universo de mujeres complejo y heterogéneo que puede generar un proceso político de reconocimientos mutuos y de construcciones de alianzas y solidaridades [...] (Galindo, 2006: 37-38).

Son igualmente interesantes, más recientemente en los años 2000, los estudios en Francia de Elsa Dorlin a propósito de la articulación de las relaciones de poder en sus análisis de género, y que habla de los peligros de la dispersión del sujeto histórico ante la concurrencia de sus diferentes categorías de dominación (Dorlin, 2009: 11). Al mismo tiempo, esta perspectiva alude a la intervención de las instancias de poder, como las políticas públicas, en el sentido de tal dispersión de la subjetivación. "Si me permiten hablar...", mediante un discurso estructurado en la visión marxista, al margen de la experiencia de clase, no deja de dar cuenta de una serie de violencias domésticas, físicas y sicológicas, económicas y sexuales propias del género. El yo-pueblo, voz de un "nosotros, los mineros explotados", revela frecuentemente en su testimonio el gran desprecio de esos mineros explotados por sus compañeras de lucha:

"Nos vamos a reunir, nos vamos a organizar en un frente". Y así lo hicieron. Se organizaron, nombraron un directorio y llamaron a la organización "Comité de Amas de Casa de Siglo XX". Eran unas sesenta mujeres.

Pero... había que ver la carcajada que en ese entonces echaron los varones. Y decían: “¿Las mujeres se han organizado en un frente! ¡Déjenlas! Ese frente no va a durar ni 48 horas. Entre ellas se van a hacer el frente y allí mismo va a terminar todo". (Viezzer, 1978: 79).

No obstante, la "historia inmediata" del texto cuenta también la evolución de la percepción masculina en cuanto a esta organización que desde su creación en 1961, dio pruebas inmensas de consecuencia y incluso de una temeridad que sorprendía a dirigentes sindicales de talla nacional, como Juan Lechín Oquendo ${ }^{7}$.

Pese a la ausencia de análisis de la transversalidad de la palabra machista en desmedro de categorías de clase cerradas, Si me permiten hablar...deja translucir, de todas formas, la presencia de esa voz despreciativa y agresiva tanto en el discurso de militares, policías pero también de los compañeros de lucha, como se puede leer en numerosas evocaciones del Comité de amas de casa. Por otra parte, el relato denuncia discreta pero evidentemente la violencia gubernamental del discurso machista centrado en el cuerpo "pecaminoso" de la mujer. Como en el relato del segundo encarcelamiento de Domitila Chungara, durante una de las sesiones de tortura por parte de un militar ebrio, hijo de un coronel, quien

\footnotetext{
${ }^{7}$ Como narra el episodio sobre la toma de rehenes extranjeros por dirigentes mineros, cuando la vigilancia de estos rehenes y el control de la situación fueron relegados al Comité de amas de casa. (Viezzer, 1978: 85-95).
} 
hizo alusiones amenazantes de violación mediante el argumento de que una mujer así de tumultuosa sólo podía estar buscando y deseando eso (Viezzer, 1978: 157).

Entretejiendo el itinerario de enfrentamientos y resistencias, la narradora revela, al margen de la ausencia de análisis teórico en materia de género, dentro de la diversidad de las voces machistas, una unicidad de la percepción genérica. La leemos por ejemplo en el mismo capítulo, cuando después de la tortura, estando Domitila embarazada y habiendo perdido a su hijo en tales circunstancias, un soldado la auxilia en la celda para después reprocharle lo siguiente:

-¿A qué te atienes, hija? Vos, siendo mujer, estando embarazada, ¿por qué no te callas? ¿Para qué has hecho eso al hijo del coronel? ¿A qué te atienes? Las mujeres, ¿por qué son así de rebeldes?

(Viezzer, 1978: 165).

La apelación al silencio como atributo femenino, la convicción de una "esencia femenina" que supone discreción y resignación, aparece en la voz de esta alma caritativa bajo la forma de una garantía de integridad física y sicológica para las mujeres. Este discurso piadoso, paternalista y moralizador de quien auxilia a Domitila, es un llamado al orden patriarcal que salvaría de la violencia a quienes se le someten. "Si me permiten hablar..." es -desde el título, no excento de ironía- una crítica permanente de tal "silencio femenino" por parte de quien -desde su lugar subalterno y explotado- no deja de alzar su voz y, por ende, de cuestionar y de desestabilizar tal esencialismo, y particularmente mediante el relato de la estupefacción de sus opositores. Como en el ejemplo que sigue, cuando el gerente regional de las minas de Siglo XX, al momento de destituir de su puesto al marido de Domitila a causa del activismo de la misma, le dice:

Ahora vas a aprender a dominar a tu mujer. Primero: tu mujer ha estado presa, y en vez de estar callada, ha vuelto peor: sigue agitando, sigue metiendo cizaña entre la gente. [...] ¡Es demasiado esa mujer! Ni parece una mujer" (Viezzer: 150-151).

Así aparecen en el relato de Domitila, la condescendencia, el desprecio, la deslegitimación de la mujer que alza la voz o su llana descalificación como mujer, como mecanismos velados o manifiestos de la dominación. Estos se expresan tanto en la boca de militares, buenos o malos, crueles o piadosos, policías, agentes del gobierno, como en la boca de mujeres diversas, burguesas o mujeres apegadas a la Iglesia.

E igualmente, como contraparte, la voz de la minera, expresa también el desprecio por las reivindicaciones de prostitutas o lesbianas que descubre en el evento internacional (Viezzer, 1978: 220), por considerarlas reivindicaciones menores en relación a la coyuntura urgente de la lucha de clases. Esta posición despreciativa -proveniente esta vez de la narradora- marca otro de los desencuentros entre las voces de mujeres. 
Domitila Chungara no relaciona su posición a la lucha feminista que conoció; primeramente porque ella asocia esta última a una reivindicación burguesa, es decir enemiga de clase; y segundamente, porque al centrarse este feminismo en la identidad biológica femenina, provoca un antagonismo hacia el hombre que invalidaría o debilitaría toda lucha social de hombres y mujeres. Pese a ello la reivindicación de la autodeterminación de la mujer a través de una vida de lucha, así como la denuncia de su experiencia como víctima de diferentes violencias específicas que se ejercen sobre ella, como mujer, aparecen de canto a canto en este testimonio.

Si me permiten hablar..., en los años 70, saca a relucir en su relato y de una manera plural y multifacética por tratarse de hechos que van aconteciendo dentro una vida y de una historia en movimiento, lo que la teoría feminista tardará mucho más en tratar: el asunto de la interseccionalidad de la opresión femenina. Puesto que, si bien es la categoría de clase la que la protagonista piensa como determinante del sometimiento, su experiencia narrada deja ver la transversalidad de los mecanismos de dominación, vehiculados por un lado y por el otro de las categorías genéricas o sociales.

Después de 39 años de la aparición de este clásico de la literatura boliviana, interpela la cuestión del desencuentro discursivo de las identidades oprimidas. En primer lugar, el menosprecio e incluso la invisibilización de la opresión femenina por parte del discurso marxista del proletariado minero que Domitila Chungara pone de relieve en su testimonio. Un discurso que aborda la opresión de la mujer como una consecuencia más de la "superestructura" de la opresión capitalista y que la trata como una opresión digna de atención únicamente en el marco de la consideración de la lucha obrera.

En segundo lugar, y tal vez con mayor importancia en el marco de este análisis, surge la cuestión de los desencuentros entre los discursos que alzan la causa de las mujeres. La oposición de Domitila Chungara al feminismo que limitó en aquel momento su palabra y que ella denunció como ocultador de las diferencias sociales y económicas entre las mujeres, persistió en la voz de esta luchadora hasta sus últimas intervenciones públicas. Tras el advenimiento de la democracia en 1982, Domitila Chungara, alejada del sector minero por el cierre de las minas estatales en 1985, pero siempre cerca de la militancia sindical y de la educación popular, insiste en la idea del peligro que el feminismo encarnaba para ella: un verdadero riesgo de división o debilitamiento de las luchas sociales y políticas.

Este hecho, considerando además la talla histórica de Domitila Chungara, conduce a una gran interrogación sobre la inaudibilidad del discurso feminista de su época en los sectores oprimidos como fue el que representaba la minera; una inaudibilidad que atañe también a cierta intelectualidad. Este testimonio no deja de señalar el desprecio de tales discursos hacia los sectores populares, como raíz de las distancias y las posiciones cerradas de uno/a/s y otro/a/s. Una cuestión que esta escritura, dentro de 
sus propias contradicciones, orienta en el sentido de la interseccionalidad de la dominación. Domitila Chungara dio cuenta con su testimonio de un verdadero itinerario del proceso de subjetivación plural. La estructuración del testimonio por parte de una teórica de las ciencias sociales como es Moema Viezzer, contribuyó seguramente a este apego al modelo de la historia inmediata en la construcción del sujeto histórico, lo que Domitila denomina en repetidas ocasiones como la "búsqueda de sí misma” y el "encuentro consigo misma" en su compromiso social. Su retórica marxista y su fe exaltante en el triunfo del socialismo en Bolivia, pese a la actual coyuntura progresista, conlleva el sabor amargo de la destrucción de estructuras poderosas de combate y resistencia como fueron los sindicatos mineros en Bolivia junto a los corajudos Comités de amas de casa.

Queda el cuestionamiento sobre la circulación de la palabra crítica y transgresora, dentro de los intentos de las lecturas en intersección y transversalidad. La búsqueda de herramientas epistemológicas para (re)pensar la dominación aparece tras la lectura de este libro de 1977 que expresa una fe de otro tiempo en cuanto a las estructuras de lucha, pero que al mismo tiempo, por su libre andar por las experiencias vividas, dice -incluso entre las líneas de una palabra tradicionalista- los deslices, la ironía, la crítica, las violencias aminoradas, la rotunda impureza constitutiva de las relaciones de poder. 


\section{Bibliografía}

Dorlin, Elsa (eda.) (2009). Sexe, Race, Classe: pour une épistémologie de la domination. Paris, PUF.

Galindo, María (2006). “Indias, putas y lesbianas, juntas, revueltas y hermanadas. ¡Un libro sobre Mujeres Creando! Monasterios, Elizabeth (eda.). No pudieron con nosotras: el desafio del feminismo autónomo de Mujeres creando. La Paz: University of Pittsburgh/Plural: 27-59.

Foucault, Michel (1994). Dits et écrits, IV, 1954-1988. Paris: Gallimard.

Gros, Frédéric (2010: 4ª ed.). Michel Foucault. Paris: PUF, Col. «Que sais-je? »

Revel, Judith (2008). Dictionnaire Foucault. Paris: Ellipses.

Viezzer, Moema (1978). Si me permiten hablar... Testimonio de Domitila, una mujer de las minas de Bolivia. México D. F.: Siglo XXI. 